\title{
EFEK KEGAGALAN ALAT FLUE GAS DESULPHUR TERHADAP TEGANGAN LEWAT DENYAR ISOLATOR DI GARDU INDUK PEMBANGKITAN TANJUNG JATI B JEPARA
}

\author{
${ }^{1}$ Tedy Juliandhy, ${ }^{2}$ T.Haryono, ${ }^{3}$ Suharyanto \\ ${ }^{1}$ Program Pascasarjana Teknik Elektro dan Informatika, Fakultas Teknik \\ Universitas Gadjah Mada \\ ${ }^{2,3}$ Staff pengajar, Program Pascasarjana Teknik Elektro dan Informatika, Fakultas Teknik \\ Universitas Gadjah Mada
}

\begin{abstract}
ABSTRAK - Tegangan Lewat denyar ( flashover ) adalah fenomena pelepasan muatan bersifat merusak yang melintasi seluruh bagian permukaan isolator. Pelepasan muatan ini disebabkan pembebanan medan listrik pada permukaan isolator yang melebihi harga ketahanan elektriknya. Penyebab terjadinya tegangan lewat denyar adalah pengotoran permukaan isolator, hujan asam, surja hubung dan surja petir. Salah satu penyebab Kegagalan isolasi pada isolator tegangan tinggi di Gardu induk Tanjung Jati B Jepara adalah timbulnya hujan asam akibat kondensasi asap yang keluar dari cerobong PLTU Tanjung Jati B. Hujan asam timbul karena kegagalan peralatan Flue Gas Desulphur ( FGD ) yang dipasang di PLTU untuk mengurangi gas emisi sebagai persyaratan pembangkit listrik ramah lingkungan yang diprogramkan pemerintah melalui departemen Lingkungan Hidup. Tindakan nyata ini dilakukan untuk menepis anggapan bahwa PLTU dengan bahan bakar batubara merupakan salah satu industri yang mengeluarkan gas emisi SOx dan NOx yang tinggi pada proses operasionalnya. Efek gas emisi ini merupakan salah satu penyebab terjadinya hujan asam pada lingkungan. Banyaknya kadar keasaman hujan asam yang terjadi di daerah industri akan selalu berpengaruh terhadap jaringan listrik tegangan tinggi yang sedang beroperasi menyalurkan daya listrik. Adakalanya fungsi peralatan tegangan tinggi seperti isolator di gardu induk yang menyalurkan daya listrik pada jaringan SUTET $500 \mathrm{kV}$ pada jaringan JAMALI di pulau Jawa terganggu dalam sistim operasinya karena polutan yang menempel di isolator. Hujan dengan $\mathrm{pH}$ antara $4-5$ dikategorikan sebagai hujan asam dan pada pengujian ini mempengaruhi penurunan tegangan saat terjadinya flashover sebesar $145.5 \mathrm{kV}-142.5 \mathrm{kV}$ dari tegangan kerja, hal ini menyebabkan isolator sebagai bahan isolasi dapat diperkecil jarak rayap permukaan isolatornya sehingga dapat berpengaruh terhadap ketahanan suatu isolator dalam menjalankan fungsinya sebagai alat untuk menahan terjadinya kegagalan tegangan lewat denyar ( Flashover ) dari bagian-bagian yang bertegangan.
\end{abstract}

Kata Kunci : Flashover, Isolator, FGD, Hujan asam, pH, SUTET, JAMALI.

\begin{abstract}
Flashover is a disorder condition that occurs in the form of sparks appearing between insulators or electrical component of high voltage. This can occur due to insulation failure of the high voltage system. Failure of insulation in high voltage insulators in Tanjung Jati B Jepara Substation is one of the causes of acid rain due to the condensation of smoke from the Tanjung Jati B power plant chimney. Acid rain arises due to failure Flue Gas Desulphur ( FGD ) devices were installed in the plant to reduce gas emissions as a condition of eco-friendly power plant that is planned by the government through the department of Environment. The real action is taken to dismiss the notion that Coal Fired Power Plant (CFPP) is one of the industries that emit SOx and NOx emissions are high on operational processes. The effects of gas emissions is one of the causes of acid rain on the environment. The amount of acidity of acid rain that occurred in the industrial area will always affect the high voltage power lines that distribute power in operation. Sometimes the equipment functions as an insulator in high voltage substations that distribute power at $500 \mathrm{kV}$ network SUTET JAMALI network on the island of Java in a system of operation is interrupted because of pollutants attached to the insulator. Rain with a $\mathrm{pH}$ between 4-5 categorized as acid rain and the test affects the time of the flashover voltage drop of $145.5 \mathrm{kV}-$ $142.5 \mathrm{kV}$ of the working voltage, this causes an insulator as insulation materials can be minimized distance insulator surface so that termites can affect the resistance of an insulator in its function as a tool to restrain the occurrence of flashover voltage from voltage parts.
\end{abstract}

Keywords : Flashover, Insulator, FGD, Acid rain, pH, SUTET, JAMALI. 


\section{PENDAHULUAN}

Pembangkit Listrik Tenaga Uap ( PLTU ) Tanjung Jati B terletak di Jepara Jawa Tengah. PLTU Tanjung Jati B memiliki 4 unit pembangkit dengan karakteristik dan spesifikasi yang sama ( 4 X 710 MW ) mensuplai sekitar 9 $\%$ total daya listrik untuk memenuhi kebutuhan daya listrik di Pulau Jawa, Bali, dan Madura. Sebagai pembangkit listrik dengan kapasitas besar maka performance dan reliability PLTU Tanjung Jati B diharapkan juga sejalan dengan program pemerintah yang merencanakan program langit biru dan Gogreen.

PLTU Tanjung Jati $B$ adalah PLTU pertama di Indonesia yang menerapkan teknologi FGD (Flue gas Desulphur). Teknologi FGD adalah teknologi yang menyerap gas emisi hasil proses pembakaran batubara di Power plant berbahan bakar batubara.

Pada jaringan hantaran udara, isolator digunakan sebagai penggantung dan penopang konduktor. Di Gardu Induk isolator digunakan sebagai pendukung peralatan tegangan tinggi seperti saklar pemisah (Disconnecting Switch ), pendukung konduktor penghubung, dan penggantung rel daya. Isolator berfungsi secara mekanik untuk menahan beban kawat saluran udara, secara elektrik mengisolasi saluran yang bertegangan dengan menara atau saluran dengan saluran sehingga tidak terjadi kebocoran arus dan dalam gradien medan tinggi terjadi lompatan listrik baik lewat denyar (flashover ) atau percikan ( sparkover). Salah satu faktor yang mempengaruhi proses kegagalan isolator adalah hujan asam . Keandalan isolator pasangan luar sangat berhubungan dengan keandalan sistim pembangkitan di PLTU Tanjung Jati B. Dengan keandalan dan perawatan yang berkala diharapkan tingkat keandalan PLTU tanjung jati B dapat dipertahankan dan dapat mensuplai daya listrik ke dalam jaringan JAMALI $500 \mathrm{kV}$.

\section{TINJAUAN PUSTAKA}

Isolator berfungsi secara mekanik untuk menahan beban kawat saluran udara, secara elektrik mengisolasi saluran yang bertegangan dengan menara atau saluran dengan saluran sehingga tidak terjadi kebocoran arus dan dalam gradien medan tinggi terjadi lompatan listrik baik lewat denyar (flashover) atau percikan ( sparkover ) [2], [6], [11], [12], [15], [16].

Kegagalan alat Flue Gas Desulphur ( FGD ) sebagai alat penyerap gas buang pada Pembangkit Listrik Tenaga Uap ( PLTU ) modern $[3,18]$ yang dipasang di PLTU Tanjung Jati $\mathrm{B}$, mengakibatkan peningkatan gas buang seperti $\mathrm{NH} 4 \mathrm{Cl}, \mathrm{HNO} 3, \mathrm{MgSO} 4, \mathrm{SOx}, \mathrm{NOx}$ [1], [2],[5],[13] . Akibat kegagalan ini maka kondisi lingkungan di sekitar Pembangkitan Tanjung Jati $B$ terjadi hujan asam yang timbul dari proses kondensasi dari gas buang yang dikeluarkan cerobong ( chimny) PLTU.

Hujan asam [4], [13],[14], [16] yang terjadi dilingkungan Gardu Induk (GI ) Tanjung Jati B menimbulkan tegangan lewat denyar, corona, percikan dan arus bocor [9],[10], [15],[16]. Kondisi ini dapat mengakibatkan gangguan dan menurunkan keandalan ( reliability) pada PLTU Tanjung Jati B dalam menyalurkan daya listrik pada sistim transmisi $500 \mathrm{kV}$ dan transmisi 150 $\mathrm{kV}$.

Untuk mengetahui efek dari kegagalan alat FGD maka dilakukan pengujian terhadap isolator rantai type single tension di laboratorium listrik Tegangan Tinggi Universitas Gadjah Mada. Pengujian ini dilakukan untuk mengetahui besarnya tegangan lewat denyar, arus bocor dan pengaruh derajat keasaman ( $\mathrm{pH})$ larutan kontaminasi pada isolator .

Dari hasil pengujian laboratorium diharapkan data dan informasi yang berguna bagi manajemen PLTU Tanjung Jati B untuk mengantisipasi terjadinya gangguan lewat denyar, arus bocor dan corona yang terjadi pada peralatan di Gardu induk. Dengan data yang didapat juga diharapkan dapat meningkatkan keandalan PLTU Tanjung Jati B dalam mengirim daya listrik pada jaringan $500 \mathrm{kV}$ dan $150 \mathrm{kV}$ [7,17]. Selain itu ikut sertanya partisipasi manajemen PLTU Tanjung Jati B dalam program pemerintah yaitu Langit biru dan Go green dapat terwujud dengan baik.

\section{METODOLOGI}

\section{EKSPERIMEN}




\section{A. Sampel}

Sampel yang digunakan dalam penelitian ini adalah isolator gantung tipe rantai, seperti dapat dilihat pada gambar 1 dibawah ini :

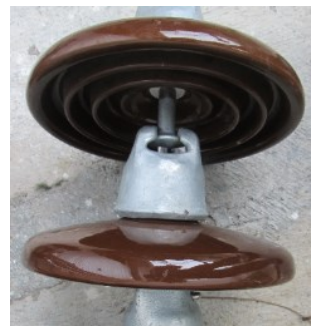

Gambar 1 Isolator rantai $50 \mathrm{kV}$

Spesifikasi isolator yang dipakai :
Type
: Single tension

Working Voltage : $50 \mathrm{kV}$

B. Peralatan pengujian tegangan lewat denyar (flashover voltage) dan arus bocor (leakage current ) terdiri :

Trafo uji : $380 \mathrm{~V} / 400 \mathrm{kV}, 400 \mathrm{kVA}, 1$ Phasa

Regulator : 220V/0-380V, $60 \mathrm{kVA}, 1$ Phasa dan Reaktor : 380V, $50 \mathrm{kVAR}$, $131.5 \mathrm{~A}$

yang ditunjukkan pada gambar .2 berikut :

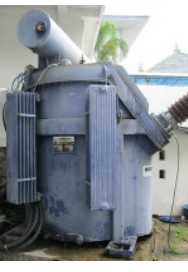

( a )

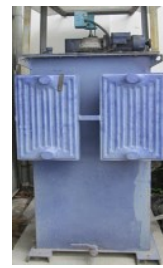

( b )

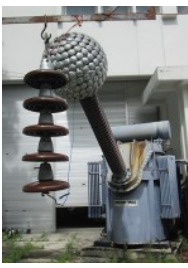

(c)
Gambar 2 Trafo uji ( a ), Regulator dan reaktor trafo (b), rangkaian uji (c )

C. Pengujian tegangan lewat denyar (flashover voltage) dan arus bocor (leakage current) dilakukan masing-masing 5 tahapan pengujian isolator yaitu :

1. Pengujian kondisi kering

2. Pengujian kondisi basah dengan $\mathrm{pH} 6.0$

3. Pengujian kondisi basah dengan $\mathrm{pH} 5.0$

4. Pengujian kondisi basah dengan $\mathrm{pH} 4.0$

5. Pengujian kondisi basah dengan $\mathrm{pH} 3.5$

\section{Sistim PENGUJIAN}

Gambar 3 berikut ini menunjukkan sistim pengujian di Laboratorium Tegangan Tinggi Universitas Gadjah Mada.

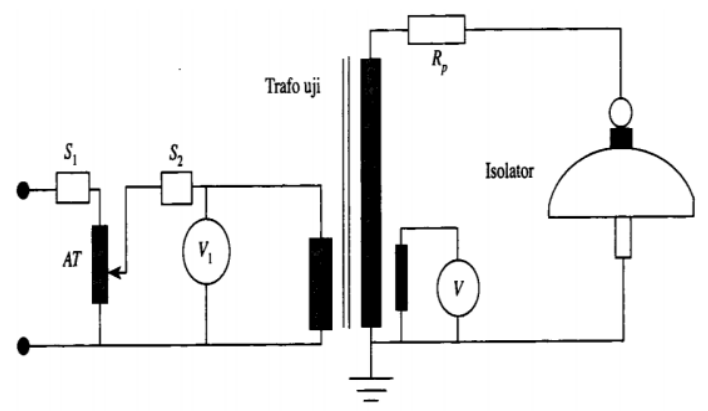

Gambar 3 Rangkaian pengujian

Isolator rantai diberi simulai curah hujan asam dengan tingkat keasaman ( $\mathrm{pH}$ ) yang berbedabeda sesuai dengan tahapan pengujian. Tegangan masing-masing pengujian isolator tersebut dinaikan secara bertahap dengan dimulai dari tegangan $55 \mathrm{kV}$ dan dinaikan sampai terjadi tegangan kritis lewat denyar ( flashover). Sedangkan untuk pengukuran arus bocor ( leakage current) dilakukan dengan mengukur arus bocor pada saat isolator uji diberi tegangan awal $55 \mathrm{kV}$ dan dinaikkan secara bertahap sampai $100 \mathrm{kV}$ untuk keamanan peralatan ukur listrik laboratorium.

\section{HASIL DAN PEMBAHASAN}

A. Tegangan Lewat Denyar ( $\mathrm{Vb})$

Besarnya nilai tegangan lewat denyar merupakan hasil rata-rata dari tiga kali percobaan, hasilnya dapat dilihat pada tabel 1 Aon grafik 4, 5 di bawah ini :

Tabel 1 Hasil pengujian tegangan flashover ( $\mathrm{Vb}$ )

\begin{tabular}{|c|c|c|c|c|c|}
\hline $\begin{array}{c}\text { Data } \\
\text { Pengujian } \\
\text { ke }\end{array}$ & $\begin{array}{c}\text { Vb } \\
\text { Kering } \\
(\mathbf{k V})\end{array}$ & $\begin{array}{c}\text { Vb } \\
\text { Basah } \\
\text { pH } \\
6.0 \\
(\mathrm{kV}) \\
\end{array}$ & $\begin{array}{c}\text { Vb } \\
\text { Basah } \\
\text { pH } \\
5.0 \\
(\mathbf{k V}) \\
\end{array}$ & $\begin{array}{c}\text { Vb } \\
\text { Basah } \\
\text { pH } \\
4.0 \\
(\mathbf{k V})\end{array}$ & $\begin{array}{c}\text { Vb } \\
\text { Basah } \\
\text { pH } \\
3.5 \\
(\mathrm{kV})\end{array}$ \\
\hline 1 & 310.4 & 154.6 & 147.5 & 145.9 & 142.5 \\
\hline 2 & 292.4 & 150.2 & 145.2 & 144.6 & 141.3 \\
\hline 3 & 290.8 & 144.8 & 143.8 & 138.3 & 139.8 \\
\hline $\begin{array}{c}\text { Vb } \\
\text { Rata-rata }\end{array}$ & 297.9 & 149.9 & 145.5 & 142.9 & 141.2 \\
\hline
\end{tabular}

Ket : Vb adalah Flashover Voltage ( Tegangan lewat denyar ) yang terjadi 


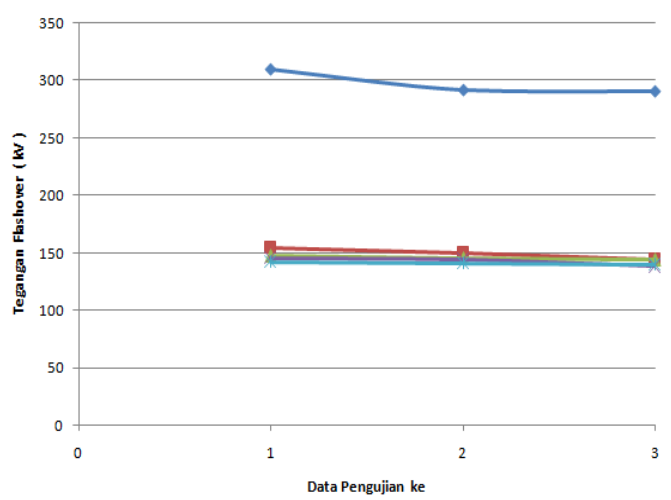

Gambar 4 Grafik hasil pengujian tegangan flashover $(\mathrm{Vb})$

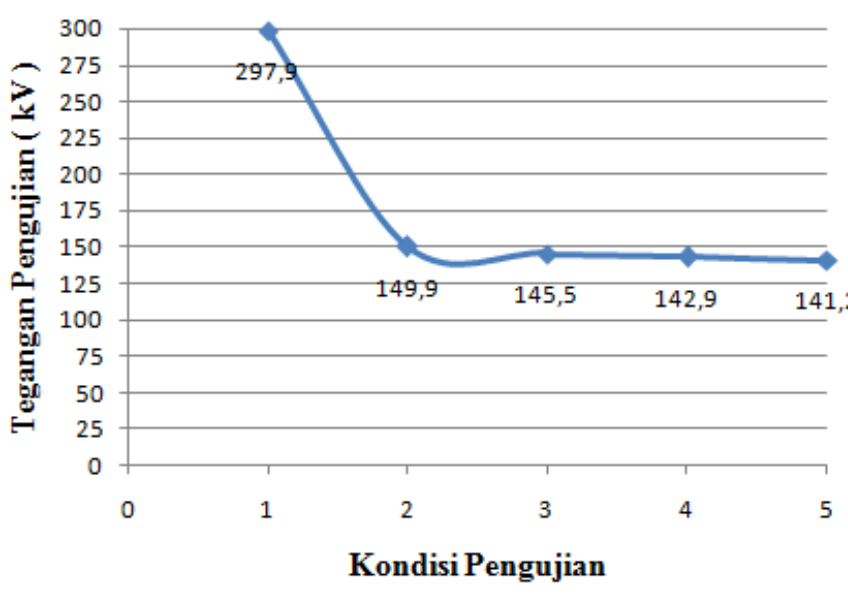

Gambar 5 Grafik Pengujian Tegangan flashover rata-rata.

Dari data di atas dapat diketahui bahwa semakin tinggi derajat keasaman $(\mathrm{pH})$ larutan yang mengkontaminasi isolator, semakin kecil/menurun nilai tegangan lewat denyarnya ( flashover voltage ). Pada pengujian satu sampai ke tiga dengan kondisi pengujian tertentu terlihat penurunan tegangan lewat denyar, ini disebabkan karena pada isolator saat pengambilan data ke satu saat terjadi flashover muncul jalur pita kering corona. Jalur pita kering corona semakin menurunkan tegangan flashover pada pengujian berikutnya dalam kondisi pengujian yang sama. Pita kering corona semakin menurunkan tegangan flashover pada saat pengujian dalam kondisi basah dengan larutan kontaminasi yang memiliki derajat keasaman ( $\mathrm{pH}$ ) semakin tinggi.

Pengujian kategori hujan asam pada $\mathrm{pH} 5$ 4, tegangan flashover rata-rata semakin turun dari $145.5 \mathrm{kV}$ menjadi $142.93 \mathrm{kV}$. Apabila kondisi ini diabaikan tanpa adanya condition monitoring akan menimbulkan turunnya tingkat keandalan

( reliability ) PLTU dalam menyalurkan energi listrik pada jaringan transmisi karena adanya force outage ( perawatan diluar jadwal ) isolator yang mengalami flashover dan corona.

Menurut IEC 815 jarak rambat minimum dari isolator adalah [8] :

$$
1_{\mathrm{n}}=\mathrm{JRSx} \mathrm{V} \times \mathrm{k}_{\mathrm{d}}
$$

dengan :

$1_{\mathrm{n}}=$ Jarak rambat nominal minimum $(\mathrm{mm})$

$\mathrm{J}_{\mathrm{RS}}=$ Jarak rambat spesifik minimum $(\mathrm{mm} / \mathrm{kV})$

$\mathrm{V}=$ Tegangan sistim tertinggi fasa ke fasa ( $\mathrm{kV}$ )

$\mathrm{kd}=$ faktor koreksi yang tergantung pada diameter isolator

\section{A. Arus bocor ( $\mathrm{Ib}$ )}

Besarnya nilai arus bocor merupakan hasil yang diambil pada saat pengujian dengan memberikan isolator uji dengan tegangan di mulai $55 \mathrm{kV}$ dan dinaikan secara bertahap sampai tegangan maksimal $100 \mathrm{kV}$ untuk keamanan peralatan ukur listrik yang digunakan. Pada setiap kenaikan tegangan $5 \mathrm{kV}$, data arus bocor yang diambil hasilnya dapat dilihat pada tabel 2 dan gambar 6,7 berikut :

Tabel 2 Arus bocor ( Ib )

\begin{tabular}{|c|c|c|c|c|c|}
\hline $\begin{array}{c}\text { Tegangan } \\
\begin{array}{c}\text { Pengujian } \\
(\text { kV })\end{array}\end{array}$ & $\begin{array}{c}\text { Ib } \\
\text { kondisi } \\
\text { Kering } \\
\text { ( mA })\end{array}$ & $\begin{array}{c}\text { Ib } \\
\text { kondisi } \\
\text { Basah } \\
\text { pH 6.0 } \\
(\text { mA })\end{array}$ & $\begin{array}{c}\text { Ib } \\
\text { kondisi } \\
\text { Basah } \\
\text { pH 5.0 } \\
(\text { mA })\end{array}$ & $\begin{array}{c}\text { Ib } \\
\text { kondisi } \\
\text { Basah } \\
\text { pH 4.0 } \\
(\text { mA })\end{array}$ & $\begin{array}{c}\text { Ib } \\
\text { kondisi } \\
\text { Basah } \\
\text { pH 3.5 } \\
(\text { mA })\end{array}$ \\
\hline 55 & $\mathbf{0 . 4 8}$ & $\mathbf{0 . 5 1}$ & $\mathbf{0 . 5 4}$ & $\mathbf{0 . 5 7}$ & $\mathbf{0 . 6 1}$ \\
\hline 60 & $\mathbf{0 . 5 3}$ & $\mathbf{0 . 5 5}$ & $\mathbf{0 . 5 9}$ & $\mathbf{0 . 6 1}$ & $\mathbf{0 . 6 5}$ \\
\hline 65 & $\mathbf{0 . 5 8}$ & $\mathbf{0 . 5 9}$ & $\mathbf{0 . 6 0}$ & $\mathbf{0 . 6 5}$ & $\mathbf{0 . 7 0}$ \\
\hline 70 & $\mathbf{0 . 6 2}$ & $\mathbf{0 . 6 4}$ & $\mathbf{0 . 6 5}$ & $\mathbf{0 . 6 9}$ & $\mathbf{0 . 7 2}$ \\
\hline 75 & $\mathbf{0 . 6 7}$ & $\mathbf{0 . 6 9}$ & $\mathbf{0 . 6 8}$ & $\mathbf{0 . 7 2}$ & $\mathbf{0 . 7 5}$ \\
\hline 80 & $\mathbf{0 . 7 1}$ & $\mathbf{0 . 7 2}$ & $\mathbf{0 . 7 3}$ & $\mathbf{0 . 7 5}$ & $\mathbf{0 . 8 1}$ \\
\hline 85 & $\mathbf{0 . 7 6}$ & $\mathbf{0 . 7 7}$ & $\mathbf{0 . 7 8}$ & $\mathbf{0 . 7 9}$ & $\mathbf{0 . 8 4}$ \\
\hline 90 & $\mathbf{0 . 8 1}$ & $\mathbf{0 . 8 2}$ & $\mathbf{0 . 8 3}$ & $\mathbf{0 . 8 4}$ & $\mathbf{0 . 8 7}$ \\
\hline 95 & $\mathbf{0 . 8 5}$ & $\mathbf{0 . 8 6}$ & $\mathbf{0 . 8 7}$ & $\mathbf{0 . 8 9}$ & $\mathbf{0 . 9 0}$ \\
\hline 100 & $\mathbf{0 . 9 0}$ & $\mathbf{0 . 9 2}$ & $\mathbf{0 . 9 3}$ & $\mathbf{0 . 9 4}$ & $\mathbf{0 . 9 6}$ \\
\hline
\end{tabular}

Ket $:$ IEC = International Elecrotechnical Commission $\mathrm{Ib}=$ Arus bocor 


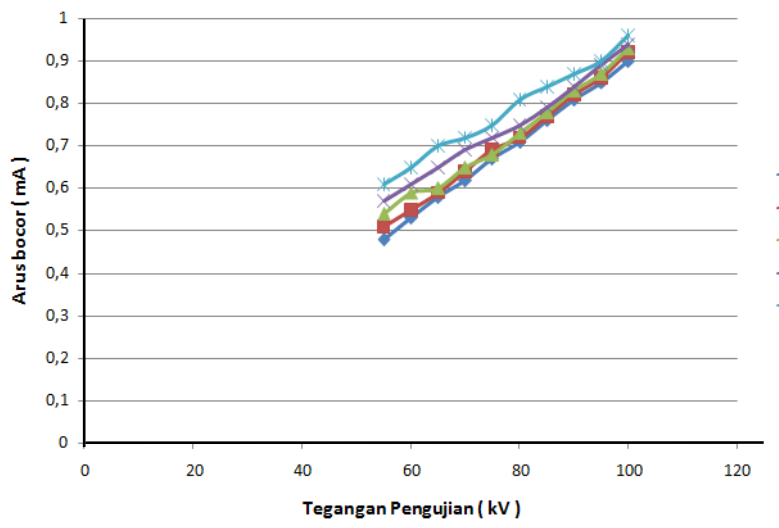

Gambar 6 Grafik arus bocor ( Ib )

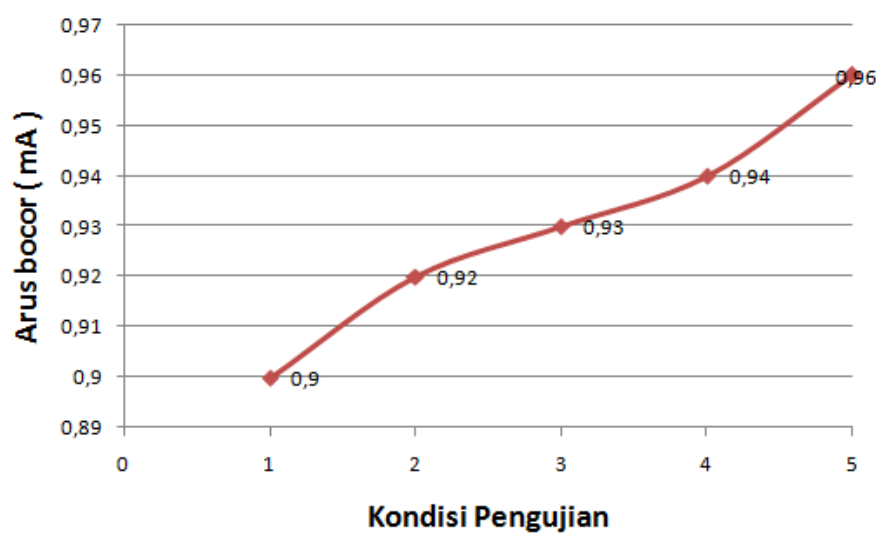

Gambar 7 Grafik Arus bocor ( Ib ) pada tegangan 100 $\mathrm{kV}$

Dari data pengujian arus bocor di atas dapat diketahui bahwa semakin tinggi derajat keasaman ( $\mathrm{pH})$ larutan yang mengkontaminasi isolator, semakin besar nilai arus bocor ( Ib ) yang terjadi pada isolator uji.

Arus bocor akan mengalir ke bagian yang bersifat konduktif pada permukaan isolator saat isolator terdapat beda tegangan. Bila isolator dalam keadaan lembab dengan bagian permukaan isolator berpolutan atau terkontaminasi maka yang paling konduktif sehingga arus bocor akan mengalir melaluinya. Mengalirnya arus bocor yang terus menerus ini akan menimbulkan adanya tegangan flashover. Tegangan ini apabila terjadi berulang kali akan menimbulkan panas pada permukaan bahan isolator. Nilai tahanan pada bahan isolator terhadap arus bocor berbanding terbalik sehingga semakin besar nilai tahanan maka besarnya arus bocor semakin kecil. Hal ini menyebabkan sifat gaya tarik menarik antara molekul-molekul di permukaan bahan isolator dengan kontaminan polutan semakin tinggi.
Semakin tinggi sifat adhesivitas antara molekul kedua bahan akan menyebabkan kontaminan polutan semakin mudah untuk mengalir dari elektroda bertegangan tinggi sampai elektroda $\rightarrow$-keripentanahan dan akan cepat ter-absorbsi ke $\rightarrow-$ H 6.9 Galam permukaan bahan isolator.

$\leftarrow \mathrm{pH} 4,0$

\section{*-рнз3 B. KESIMPULAN}

Berdasarkan pengujian dan analis data dapat diambil kesimpulan sebagai berikut :

1. Semakin tinggi tingkat keasaman (derajat $\mathrm{pH}$ ) suatu larutan kontaminasi yang mengenai isolator maka tegangan lewat denyar ( flashover voltage) akan semakin menurun.

2. Dengan menjaga alat FGD supaya tetap berfungsi maka force outage ( servis tanpa terjadwal ) di Tanjung Jati B akibat adanya tegangan lewat denyar, sparkover dan corona pada peralatan gardu induk dapat dicegah.

3. Pada klasifikasi hujan asam dengan tegangan kerja $150 \mathrm{kV}$ di Gardu Induk Tanjung Jati B terjadi penurunan tegangan lewat denyar. Untuk kondisi basah dengan pH 5.0 terjadi tegangan lewat denyar pada tegangan $145 \mathrm{kV}$ dan pada $\mathrm{pH} 4.0$ terjadi tegangan lewat denyar pada tegangan $142.5 \mathrm{kV}$.

4. Peningkatan suhu dan pemanasan pada isolator akibat kontaminasi hujan asam menyebabkan peningkatan arus bocor dan penurunan tegangan lewat denyar / gagal isolator.

5. Adanya cairan kontaminasi pada isolator menyebabkan fenomena tegangan gagal/lewat denyar berupa sparkover ( percikan) dan corona.

\section{DAFTAR PUSTAKA}

[1] Vosloo, WL. A Comparison of the Performance of High Voltage Insulator Materials in a Severity Polluted Coastal Environment. Ph.D Dissertation, Departement of Electrical Engineering, University of Stellenbosch, South Africa. 2002.

[2] Chuyan Zhang, Liming Wang, Zhicheng Guan, Fuzeng Zhang. Pollution Flashover Performance of Full-scale $800 \mathrm{kV}$ 
Converter Station Post insulators at High Altitude Area. IEEE: 1070-9878/13. 2013

[3] Richard D.Tabors. Coal to Natural Gas Seasonal Fuel Switching; An Option for Acid Rain Control. IEEE 08858950/89/0500-0457. 1989.

[4] Paul McGarth. Accelerated Aging of Insulators Under Acid Rain Condition. IEEE : 0-7803-5931-3/0. 2000.

[5] Mohammed Amin, Raji Sundararajan. Performace of Silicone Rubber Insulators under Acid Rain and Multistress Condition.

IEEE: 978-1-4244-8286-3/10. 2010.

[6] BX. Du, T. Han, X. Cheng, Jie Lie. Characterization of Surface Discharge as Indicator for Hydrophobicity Evaluation of Silicone Rubber Insulators. IEEE : 1070-9878/12. 2012.

[7] Nurlailati. Analisis Degradasi Permukaan Bahan Isolasi Resin Epoksi Karena Proses Penjejakan Dan Erosi. Tesis Fakultas Teknik Jurusan Teknik Elektro Universitas Gadjah Mada, Yogyakarta.2011.

[8] Ika Novia Anggraini. Pengaruh Komposisi Bahan Isolasi Resin Epoksi Dengan Bahan Pengisis Silicone Rubber Terhadap Proses Tracking Dan Erosi. Tesis Fakultas Teknik Jurusan Teknik Elektro Universitas Gadjah Mada, Yogyakarta.2010.

[9] Gorur, R. S. Et.al. A Laboratory Test for Tracking and Erosion Resistance of HV Outdoor Insulation", IEEE Transaction on Dielectrics and Electrical Insulation, Vol 4 No 6. 1997.

[10] Kugami, S dan Yoshimura, N. Tracking and Erosion of HTV Silicone Rubber and suppression Mechanism of ATH ", IEEE Transactions on Dielectric and Electrical insulation, Vol 8 No.2. 2001

[11] Hartono. Acid Rain. Paper Pasca Sarjana Universitas Indonesia 2005.

[12] Raji Sundararajan. Long Term Acid Rain Multistress Performance of Thermoplastic and Thermoset Polymeric Insulators. IEEE : 978-1-4244-6653-5/10. 2010.

[13] Valdi Rizki Yandri, Nurhatisyah. Fenomena Flashover Akibat Arus Bocor Pada Isolator Keramik dan Resin Epoxy.
Jurnal Teknik Elektro ITP Vol.2 no. 2, Juli 2012.

[14] Lanto M. Kamil Amali. Analisis Pengujian Arus Bocor Line Post Insulator $70 \mathrm{kV}$ Yang Terkontaminasi Polutan Industri. Jurnal ilmiah FORISTEK Vol. 2 no.1, Maret 2012.

[15] Diklat Pembangkitan Tanjung Jati B. Basic Trainee for power Plant. Oktober 2006.

[16] Paul Breeze. Power Generation Technologies. Page 29-30. First published 2005.

\section{Biodata Penulis}

Tedy Juliandhy lahir di Sidoarjo pada tahun 1970. Menyelesaikan jenjang S1 di FT.Teknik Elektro ITS jurusan Sistem Tenaga tahun 1993. Sekarang sedang menempuh Jenjang S2 / Pascasarjana Teknik Elektro dan Informatika, Universitas Gadjah Mada. Dinas di Medco Power Indonesia 